\title{
A Theoretical Study on the Hydrodynamics of a Zero-Pressurized Air-Cushion-Assisted Barge Platform
}

\author{
Fengmei Jing ${ }^{1}, \mathrm{Li} \mathrm{Xu}^{2}$, Zhiqun Guo ${ }^{3, *(\mathbb{D})}$ and Hengxu Liu ${ }^{3}$ \\ 1 School of Mechanical Engineering, Beijing Institute of Petrochemical Technology, Beijing 102617, China; \\ Jingfengmei@bipt.edu.cn \\ 2 Shanghai Branch, China Ship Scientific Research Center, Shanghai 200001, China; xu_li@hrbeu.edu.cn \\ 3 College of Shipbuilding Engineering, Harbin Engineering University, Harbin 150001, China; \\ liuhengxu@hrbeu.edu.cn \\ * Correspondence: guozhiqun@hrbeu.edu.cn; Tel.: +86-451-8258-9204
}

Received: 8 July 2020; Accepted: 22 August 2020; Published: 27 August 2020

check for updates

\begin{abstract}
Thebarge platform has the advantages of low cost, simple structure, and reliable hydrodynamic performance. In order to further improve the hydrodynamics of the barge platform and to reduce its motion response in waves, a zero-pressurized air cushion is incorporated into the platform in this paper. The pressure of the zero-pressurized air cushion is equal to atmospheric pressure and thus does not provide buoyancy to the platform. As compared to the conventional pressurized air cushion, the zero-pressurized one has advantages of less air leakage risk. However, due to the coupling effect on the interface between water and air cushion, the influence of the gas inside the air cushion on the performance of the floating body has become a difficult problem. Based on the boundary element method, the motion response of the zero-pressurized air-cushion-assisted barge platform under regular and irregular waves is calculated and analyzed in the paper. Compared with the barge platform without air cushion, numerical results from the theoretical method show that in regular waves, the air cushion could significantly reduce the amplitude of heave and pitch (roll) response of the round barge platform in the vicinity of resonance. In irregular waves, the air cushion also observably reduces the pitch (roll) motion, though amplifies the heave motion due to the transfer of heave resonance frequency. Thetheoretical study demonstrates that the zero-pressurized air cushion can reduce the seakeeping motion of barge platforms in high sea states, but might also bring negative effects to heave motion in low sea states. One should carefully design the air cushion for barge platforms according to the operating sea states to achieve satisfactory hydrodynamic performance in engineering application.
\end{abstract}

Keywords: barge platform; zero-pressurized air cushion; hydrodynamic performance; boundary element method

\section{Introduction}

The round barge is a common floating platform in ocean engineering. Its structure is simple, the cost is cheaper than other floating platforms, and its life is longer (about 100 years). However, due to the large waterline area of the barge, the motion response under the incident waves is also relatively large. How to improve the seakeeping performance of a barge and reduce its motion response in waves has always been the focus of research in ocean engineering.

At present, anti-roll tanks (ARTs), tunedliquid column dampers (TLCDs) and tuned mass dampers (TMDs), air cushions (ACs), heave bottom plates (HBPs), and so forth, can be used to reduce the motion of the offshore floating barge [1]. The principle of the tuned water column damper is the 
same as the anti-roll water tank, which are considered as one kind in this paper. It was reported that, as compared to other dampers, the air cushion has the most significant anti-rolling effect on the floating platform [1]. Results of studies in other literature also confirm that the air cushion has an obvious effect on improving the hydrodynamic performance of the barge-type offshore platform. The air cushion can significantly reduce the wave bending moment of the floating platform, which is because the air cushion disperses the relatively concentrated wave load [2], and chronic drift forcedue to the existence of the free surface in the air cushion makes waves relatively easy to pass through the platform $[3,4]$.

The application of air cushion technology in the field of ocean engineering has a long history, which can be traced back to the 1970s [3]. Pinkster and Fauzi studied a square air-cushion-supported structure [5]. The Green function method and three-dimensional linear radiation/diffraction theory were used to predict its motion response under waves and the air pressure inside the air cushion, and the numerical results agree well with the experimental ones [6]. Ikoma et al. [7] had studied the elastic floating platform supported by the air cushion based on the potential flow theory and pressure distribution method. The integral equation was used to calculate the movement of the internal air cushion under the regular waves. The results show that the air cushion can effectively reduce the wave drift force and the motion response of the floating platform [7]. For the verylarge floating body supported by the air cushion, Kessel analyzed its motion response based on the three-dimensional linear potential flow theory. The results suggest that this method can accurately solve the motion response of the floating body. It has been improved, and the wave bending moment acting on the structure has been significantly reduced [8]. Lee and Newman studied the wave effects of a super-large floating air cushion support platform in waves based on potential flow theory. They used a series of given Fourier modes to represent the vertical motion on the free surface in the air cushion of the air-supported floating structure, and thus extended the traditional six-freedom rigid body motion equation. The effect of air movement inside the air cushion is expressed by the derived aerodynamic added mass coefficient [9]. Lee and Newman made further improvements using the generated Fourier modals to represent changes in the internal oscillation pressure of the air cushion, which had been applied in WAMIT software [10]. Bie et al. [11] pointed out that the stability of the air-cushion-supported structure was lower than that of the common floating body under the same conditions, while the air cushion compartmentalization can improve the stability. Zhang et al. [12] conducted experimental and theoretical studies on the floating stability of an air-cushion-supported artificial island, whose foundation consists of multiple air cylinder structures.

On the other hand, the air cushion has also been applied to the ship field. Yang et al. [13] numerically and experimentally studied the seakeeping performance of a partial air-cushion-supported catamaran (PACSCAT) sailing in regular waves. Yang et al. [14] and Cucinotta et al. [15-17] investigated the air cavity and its evolution under stepped planning hulls. However, the air cushion/cavity under ships generally involves physical processes such as air inflow/generation and air leakage, which are more complicated than thoseunder platforms. Actually, the air cushion under platforms is enclosed by platform structures and free surface, and usually is isolated from atmosphere, so its hydrodynamic performance can be analyzed using simpler theoretical models.

In summary, the air cushion possessesa certain amount of displacementin the above literature, which might undergo risk of air pressure loss.On the contrary, the floating platform fitted with a zero-pressurized air cushion has a relatively high safety performance. That is because its static pressure is equal to the atmospheric pressure, and there is no need to worry about the damage or leakage of the air tanks. However, the hydrodynamic performance of the zero-pressurizedaircushion platform is rarely studied.

A round barge platform with zero-pressurized air cushion is proposed in this paper, and its hydrodynamic performance is studiedbased on the boundary element method. Firstly, the boundary conditions and control equations are constructed, and the air velocity potential is solved to obtain the air cushion aerodynamic coefficient; secondly, the barge platform motion equations are established and solved, where the hydrodynamic coefficients and wave force are obtained; finally, the influence of 
the zero-pressurized air cushion on the hydrodynamic performance of the barge platform is studied and the effect of the water depth on the air-cushion-assisted barge platform is analyzed.

\section{The Zero-Pressurized Air-Cushion-Assisted Barge Platform}

The three-dimensional model of the zero-pressurized air-cushion-assisted barge platform is shown in Figure 1, and the design parameters are shown in Table 1.

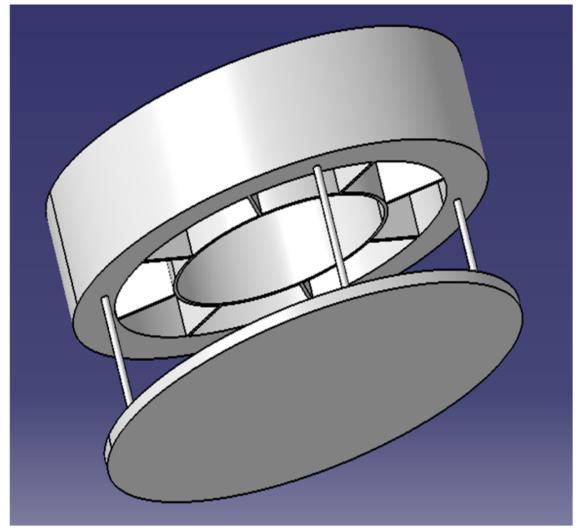

(a)

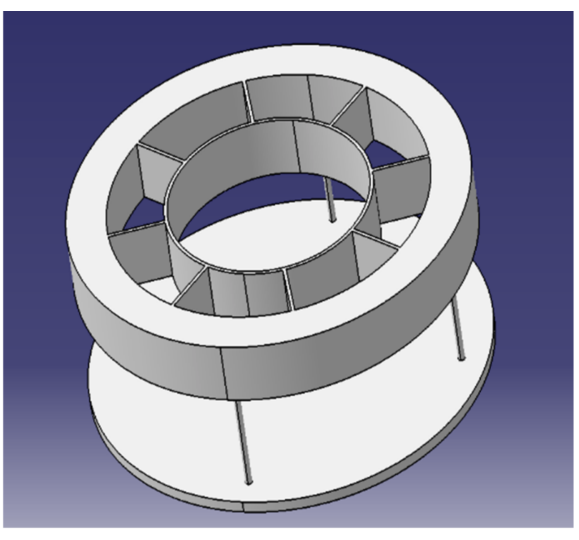

(b)

Figure 1. 3D model diagram of the zero-pressurized air-cushion-assisted barge platform. (a) Overall model diagram; (b) underwater structure model diagram.

Table 1. Parameters of the zero-pressurized air-cushion-assisted barge platform.

\begin{tabular}{ccc}
\hline Parameter & Numerical Value & Unit \\
\hline Design water depth $(\mathrm{h})$ & $\geq 30$ & $\mathrm{~m}$ \\
Outer diameter of floating tank $\left(\mathrm{d}_{1}\right)$ & $2 \times 30=60$ & $\mathrm{~m}$ \\
Outer diameter of air tank $\left(\mathrm{d}_{2}\right)$ & $2 \times 22.5=45$ & $\mathrm{~m}$ \\
Diameter of middle tank $\left(\mathrm{d}_{3}\right)$ & $2 \times 5.8=11.6$ & $\mathrm{~m}$ \\
Subdivision & Eighth Division & \\
Platform height & 25 & $\mathrm{~m}$ \\
Platform draft $(\mathrm{d})$ & 20 & $\mathrm{~m}$ \\
Platform freeboard $\left(\mathrm{h}_{\mathrm{f}}\right)$ & 5 & $\mathrm{~m}$ \\
Platform mass & 1251 & $\mathrm{t}$ \\
Ballast material & Placer/Concrete & \\
Ballast diameter $\left(\mathrm{d}_{4}\right)$ & $2 \times 30=60$ & $\mathrm{~m}$ \\
Ballast height & 0.354 & $\mathrm{~m}$ \\
Ballast mass & 2000 & $\mathrm{t}$ \\
\hline
\end{tabular}

The zero-pressurized air-cushion-assisted bargeplatform consists of a barge structure main body at the top, a ballast plate at the bottom with the function of heave damping and ballast together, and a connecting truss that connects the above two parts. The main body of the bargeplatform includes a zero-pressurized air cushion tank and a buoyancy tank. The air cushion tank is divided into eightcompartments, which are geometrically equal and symmetrical sector-annular air tanks. These eightcompartments do not provide buoyancy, but they can act as an air spring when the bargeplatform heaves to reduce the motion response of the platform. The buoyancy tank on the periphery of the air tank is a structure that mainly provides buoyancy to the platform. Various materials can also be used to enhance the structural strength of the platform. The bottom of the buoyancy tank has a ring of damping skirt to increase the damping of the platform and thus reduce the motion response in waves. The truss can move up and down through the buoyancy tank to adjust the draft of the ballast tank, which is beneficial for towing the platform through shallow water. The detailed structure of the aircushion floating platform is shown in Figures 2 and 3. 


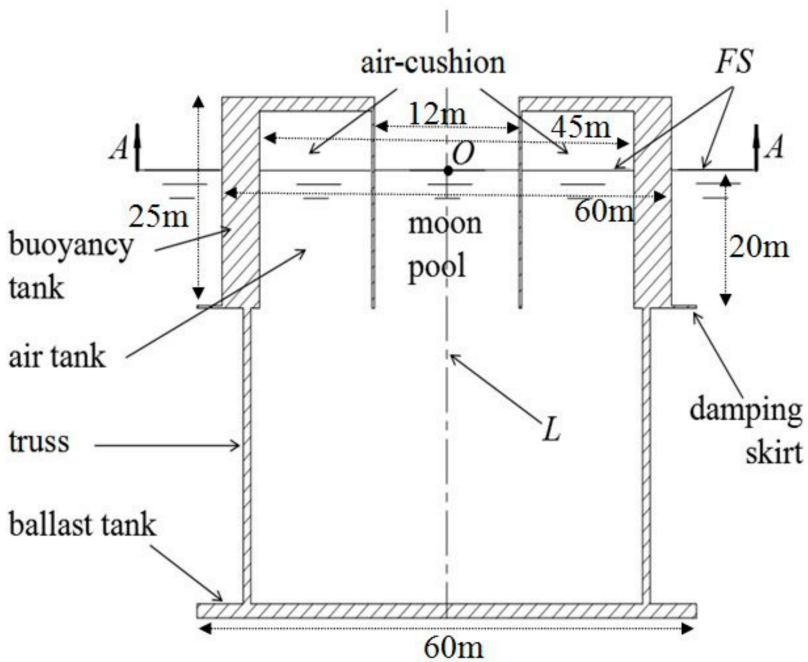

(a)

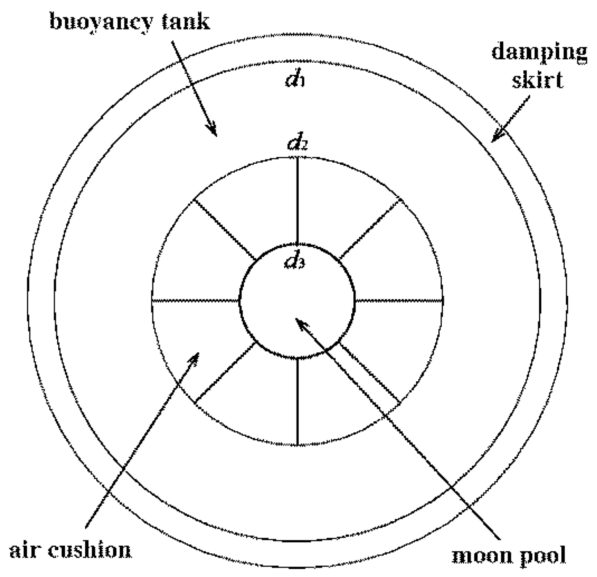

(b)

Figure 2. Schematic diagram of the zero-pressurized air-cushion-assisted barge platform. (a) Side view; (b) top view.

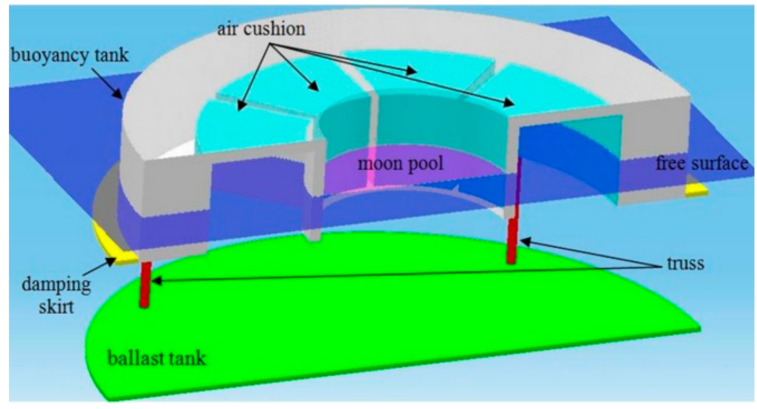

(a)

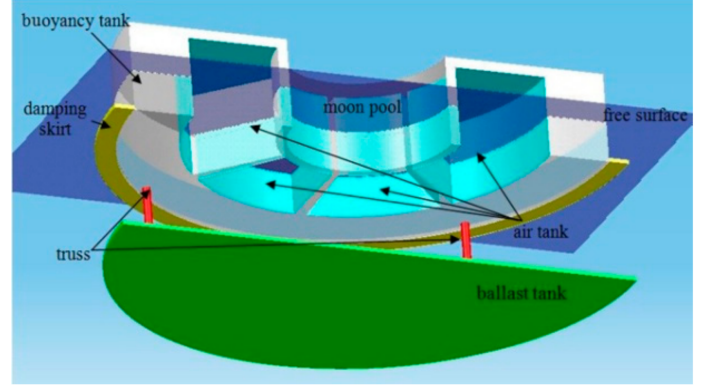

(b)

Figure 3. Schematic diagram in 3D of the zero-pressurized air-cushion-assisted barge platform. (a) Top side view; (b) bottom side view.

\section{Motion Equations of the Air-Cushion-Assisted Barge Platform}

Assuming that the fluid is ideal and the flow is irrotational, and the air in the cushion is compressible, the motion of the zero-pressurized air-cushion-assisted barge platform in the waves can be analyzed using potential flow theory. Let $S_{b}$ be the wetted surface of the barge platform, $S_{c}$ the inner surface of the platform that surrounds the air cushion, and $S_{i}$ the air-water interface under the air cushion. Then, the complete enclosed surface surrounding the air cushion is expressed as $S_{a}=S_{c}+S_{i}$; the complete boundary between the water and the barge platform can be expressed as $S_{w}=S_{b}+S_{i}$. The free surface outside the float is denoted by $S_{f}$. The height of the air tank is $h$, and the draft is $d$.

\subsection{The Definite Problem for the Air Cushion}

Within the linear frequency domain conditions, the air velocity potential in the cushion can be presented as

$$
\Psi=\operatorname{Re}\left\{\psi \mathrm{e}^{i \omega t}\right\}
$$

Obviously, the air in cushions should obey the law of mass, momentum, and energy conservation [18], from which one gets the control equation (Helmholtz equation) for $\psi$

$$
\nabla^{2} \psi+K_{a}^{2} \psi=0
$$


where $K_{a}=\frac{\omega}{c_{0}}$, and $c_{0}=\sqrt{\frac{d p}{d \rho_{a}}}$ which is the acoustic velocity under adiabatic conditions, $p$ is the atmospheric pressure, $\rho_{a}$ is the air density.

Since the air cushion in the platform is fan-shaped (as shown in Figure 4), the cylindrical coordinate system is appropriate to describe the definite problem. Let $a, b$ be the inner and outer diameter of the fan-shaped cushion, respectively. The angle between the boundary of one side and the starting coordinate axis in the positive direction is $\theta=c$, and the angle between the boundary of the other side and the starting coordinate axis in the positive direction is $\theta=d$, the height of air tank is $z_{h}-z_{l}=h$. The control equation (Helmholtz equation) satisfied by the air velocity potential in the fan-shaped air cushion in the cylindrical coordinate system can be written as

$$
\frac{1}{r} \frac{\partial}{\partial r}\left(r \frac{\partial \psi}{\partial r}\right)+\frac{1}{r^{2}} \frac{\partial^{2} \psi}{\partial \theta^{2}}+\frac{\partial^{2} \psi}{\partial z^{2}}+K_{a}^{2}=0
$$

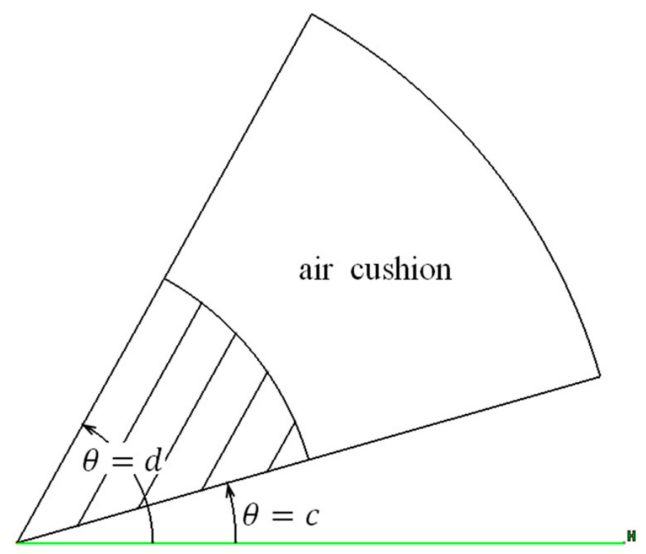

Figure 4. Top view of single fan-shaped air tank.

From the Bernoulli equation, the relationship between the air velocity potential $\psi$ and the pressure $p$ can be obtained. So the pressure on the free surface that is under the air cushion can be expressed as

$$
p\left(x, y, z_{l}\right)=-\rho g \sum_{j=7}^{6+N_{p}} \xi_{j} n_{j}(x, y)
$$

where $\rho$ is water density.

The free surface condition for the air velocity potential in the air cushion is obtained:

$$
\psi=\sum_{j=7}^{6+N_{p}} \frac{\rho g}{i \omega \rho_{a}} \xi_{j} n_{j}(x, y)
$$

According to numerical tests in literature [10], if the air cushion is not too large, the uniform pressure can obtain satisfactory results. In this paper, the CFD (Computational Fluid Dynamics) simulation result also suggests that the variation of air pressure in a cushion is no more than $0.2 \%$. Therefore, the pressure on the free surface can be assumed to be evenly distributed, that is, one can set $N_{p}=1, n_{7}(x, y)=1$.

The wall conditions for the air velocity potential in the cushion are:

$$
\frac{\partial \psi}{\partial n}=i \omega \sum_{j=1}^{6} \xi_{j} N_{j}
$$


Decomposing the air velocity potential yields

$$
\psi=i \omega \sum_{j=1}^{6+N_{p}} \xi_{j} \Phi_{j}
$$

Then the air velocity potential component $\Phi_{j}$ also satisfies the control Equation (3), and when $j \leq 6$, the following boundary conditions are obtained:

$$
\begin{cases}\frac{\partial \Phi_{j}}{\partial n}=N_{j} & \text { on } S_{c} \\ \Phi_{j}=0 & \text { on } S_{i}\end{cases}
$$

When $j \geq 7$, there exist the following relations:

$$
\begin{cases}\frac{\partial \Phi_{j}}{\partial n}=0 & \text { on } S_{c} \\ \Phi_{j}=-\frac{\rho}{\rho_{a}} \frac{\mathrm{g}}{\omega^{2}} n_{j}(x, y) & \text { on } S_{i}\end{cases}
$$

Equations (3), (8), and (9) constitute the definite Helmholtz problem for the air velocity potential in the air cushion, which can be solved by analytical or numerical methods.

For the rectangular air cushion compartments, the WAMIT software [10] that released by the Massachusetts Institute of Technology can directly give the analytical solution for the air velocity potential [11]. However, for the fan-shaped air cushion, there exists neither analytical solver nor analytical solution given in literature that can directly solve the abovementioned definite problem. To this end, the open-source program BEMHELM [19] that released by the Nantes Central Institute of Technology is employed to numerically solve the definite Helmholtz problem.

After obtaining the velocity potential $\Phi_{j}$, the air cushion pressure can be written as

$$
P(x, y, z)=\rho_{\mathrm{a}} \omega^{2} \sum_{j=1}^{6+N_{p}} \xi_{j} \Phi_{j}
$$

\subsection{Motion Equations for Air-Cushion-Assisted Barge Platform}

The air dynamic expression in frequency domain is:

$$
f_{a}=\iint_{S_{c}} P(x, y, z) \cdot N_{i} d S=\sum_{j=1}^{6+N_{p}}\left(\omega^{2} \mu_{i j}^{a}-i \omega \lambda_{i j}^{a}-C_{i j}^{a}\right) \xi_{j} \quad(1 \leq i \leq 6)
$$

$\mu_{i j}^{a}, \lambda_{i j}^{a}$, and $C_{i j}^{a}$ are aerodynamic coefficients, where $\mu_{i j}^{a}$ is the air added mass matrix; $\lambda_{i j}^{a}$ is the air damping coefficient matrix; $C_{i j}^{a}$ is the air restoring coefficient matrix.

Combining Equation (11) with Equation (10), the following expression can be obtained:

$$
\iint_{S_{\mathrm{c}}} P(\xi) N_{i} \mathrm{~d} S=\rho_{\mathrm{a}} \omega^{2} \iint_{S_{\mathrm{c}}}\left(\xi_{j} \Phi_{j}\right) N_{i} \mathrm{~d} S=\left(\omega^{2} \mu_{i j}^{a}-i \omega \lambda_{i j}^{a}-C_{i j}^{a}\right) \xi_{j}
$$

Based on the above section where the velocity potential $\Phi_{j}$ is solved, the aerodynamic coefficients can be obtained by the analytical or numerical methods.

Thus, the motion equations of the zero-pressurized air-cushion-assisted barge platform can be presented as

$$
\sum_{j=1}^{6+N_{p}}\left(-\omega^{2}\left(M_{i j}+\mu_{i j}+\mu_{i j}^{a}\right)+i \omega\left(\lambda_{i j}+\lambda_{i j}^{a}\right)+\left(C_{i j}+C_{i j}^{a}\right)\right) \xi_{j}=X_{i} \quad 1 \leq i \leq N_{p}
$$


where $M_{i j}, \mu_{i j}, \lambda_{i j}$ represent the mass matrix, added mass matrix, and damping matrix, respectively, which can be solved by using the WAMIT software [10].

\section{Motion Response of the Zero-Pressurized Air-Cushion-Assisted Barge Platform in Waves}

The motion response of the zero-pressurized air-cushion-assisted barge platform is calculated by Equation (13), where the air dynamic and hydrodynamic coefficients are obtained using the BEMHELM [19] solver and WAMIT [10] software, respectively. The principal parameters of the zero-pressurized air-cushion-assisted platform are shown in Table 2. The panel model for the WAMIT calculation was established by Multisurf [10], as shown in Figure 5.

Table 2. Parameters of the barge platform with moon pool.

\begin{tabular}{ccc}
\hline Parameter & Numerical Value & Unit \\
\hline Design water depth $(\mathrm{h})$ & $\geq 30$ & $\mathrm{~m}$ \\
Outer diameter of floating tank $\left(\mathrm{d}_{1}\right)$ & $2 \times 30=60$ & $\mathrm{~m}$ \\
Inner diameter of floating tank $\left(\mathrm{d}_{2}\right)$ & $2 \times 22.5=45$ & $\mathrm{~m}$ \\
Platform height & 25 & $\mathrm{~m}$ \\
Platform draft $(\mathrm{d})$ & 20 & $\mathrm{~m}$ \\
Platform freeboard $\left(\mathrm{h}_{\mathrm{f}}\right)$ & 5 & $\mathrm{~m}$ \\
Platform mass & 1251 & $\mathrm{t}$ \\
Ballast material & Placer/Concrete & \\
Ballast diameter $\left(\mathrm{d}_{4}\right)$ & $2 \times 30=60$ & $\mathrm{~m}$ \\
Ballast height & 0.354 & $\mathrm{~m}$ \\
Ballast mass & 2000 & $\mathrm{t}$ \\
\hline
\end{tabular}

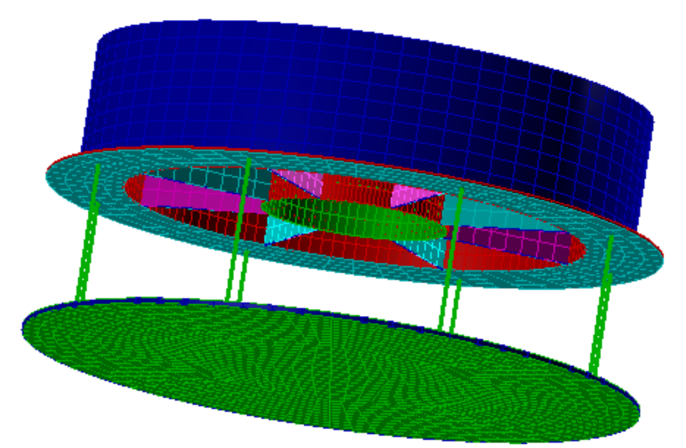

Figure 5. Panel model of the air-cushion-supported barge floating platform.

\subsection{The Influence of the Zero-Pressurized Air Cushion on the Hydrodynamic Performance of the Barge Platform}

In order to study the impact of the zero-pressurized air cushion on the hydrodynamic performance of the platform, a conventional barge platform (see Figure 6) is selected for comparison that is obtained by reducing the air cushion and its partition plates from the zero-pressurized air-cushion-assisted barge platform. The partition plate is a thin plate whose volume approximately equals to 0 . To differentiate the two platforms, the zero-pressurized air-cushion-assisted barge platform is named as "Platform with air cushion", while the conventional barge platform is named as "Platform with moon pool".

The platform with moon pool has the same displacement as the one with aircushion. The water depth is set as $60 \mathrm{~m}$, which is 3 times the platform draft. The response amplitude operators (RAOs) of the surge, heave, and pitch of the two platforms in regular waves are shown in Figure 7a-c, respectively, where the solid line denotes the results from the platform with air cushion, and the dashed lines represents those from the platform with moon pool. 


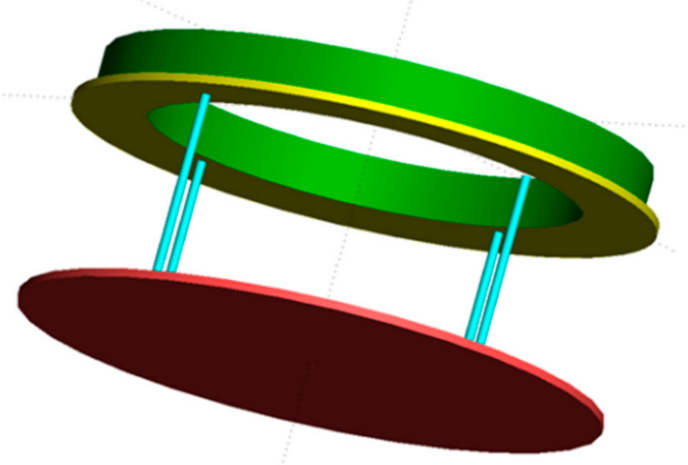

Figure 6. The platform model with moon pool.

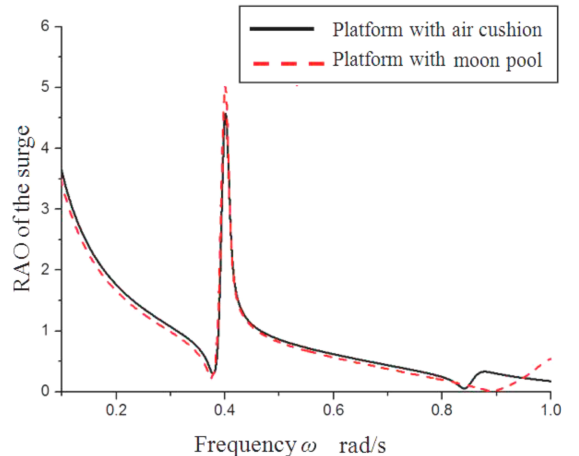

(a)

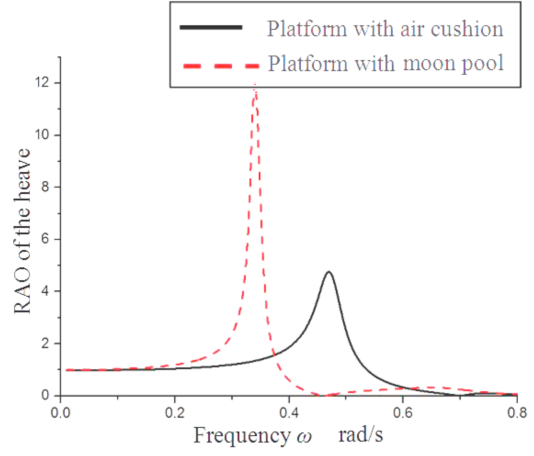

(b)

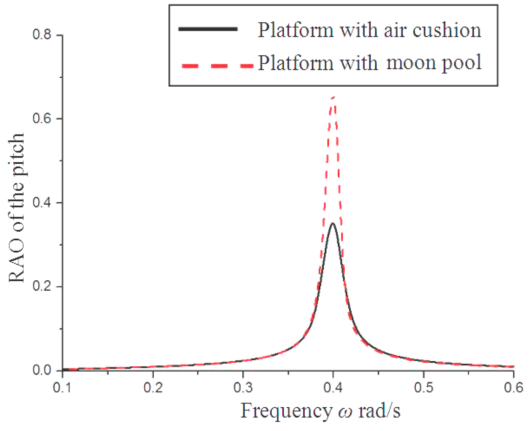

(c)

Figure 7. Comparison of RAOsbetween platform with air cushion andplatform with moon pool. (a) Surge RAO; (b) heave RAO; (c) pitch RAO.

As seen from Figure 7a, the curves of surge response from the two platforms almost coincide with each other. When the frequency is around $0.4 \mathrm{rad} / \mathrm{s}$, the RAO reaches the maximum value, and the platforms resonate in the surge direction. The surge motion resonance range of the floating platform is narrow, which is between $0.4 \mathrm{rad} / \mathrm{s}$ and $0.6 \mathrm{rad} / \mathrm{s}$. After the resonance area, the surge motion decreases rapidly with an increase of frequency. It can be found that the air cushion has little effect on the surge of the floating platform, which suggests that the air dynamics do not play an important role in the surge direction. This is because the surge motion does not change the volume of the air cushion.

As seen from Figure $7 \mathrm{~b}$, the air cushion has significant impact on the heave of the platform. The peak of the heave from the platform with air cushion is reduced about $60 \%$, as compared with the big moon pool one. The heave motion can change the volume of the air cushion and thus excites significant air dynamics. It is worth noting that the resonance frequency of the platform is shifted by the air cushion from a lower frequency (from $0.33 \mathrm{rad} / \mathrm{s}$ to $0.36 \mathrm{rad} / \mathrm{s}$ ) to a higher frequency (from $0.46 \mathrm{rad} / \mathrm{s}$ to $0.51 \mathrm{rad} / \mathrm{s}$ ). The resonance frequency of the platform with air cushion is decided by the natural 
frequency of both barge platform and air cushion. In the engineering design, the resonance frequency of the platform with air cushion can be adjusted by changing the size of the air cushion to keep away from the classical wave frequencies.However, if the size of the air cushion is not tuned properly, the air cushion might increase the heave RAO of the barge platform at higher frequencies and have a negative effect on the barge platform response, as seen in Section 4.3.

As seen from Figure 7c, the pitch amplitude of the platform in the resonance interval can also be greatly reduced by the air cushion. The maximum reduction is about $50 \%$. Obviously, in this case, the air dynamics are also excited by the change of air cushion volume due to the pitch motion. The difference between heave and pitch is that the pitch resonance frequency is not shifted by the air cushion. Except for the resonance interval, the air cushion has little impact on the pitch of the platform.

\subsection{The Influence of Water Depth on the Hydrodynamic Performance of the Zero-Pressurized} Air-Cushion-Assisted Barge Platform

The Chinese offshore water depth is around $30 \mathrm{~m}$ to $100 \mathrm{~m}$, which is comparable to the draft of the barge platform, so the water depth might have significant influence on the hydrodynamic performance of the platform in the engineering application. To evaluate this effect, the RAO of the zero-pressurized air-cushion-assisted barge platform, with theshape/dimensions of the barge kept the same as in Section 4.1, are calculated in three water depths: $32.5 \mathrm{~m}, 60 \mathrm{~m}$, and $100 \mathrm{~m}$. The RAOs of the surge, heave, and pitch of the barge platform in the regular waves are given in Figure $8 \mathrm{a}-\mathrm{c}$, respectively, where the solid lines, dashed lines, and stippling lines represent the numerical results from $100 \mathrm{~m}, 60 \mathrm{~m}$, and $32.5 \mathrm{~m}$ water depth, respectively.
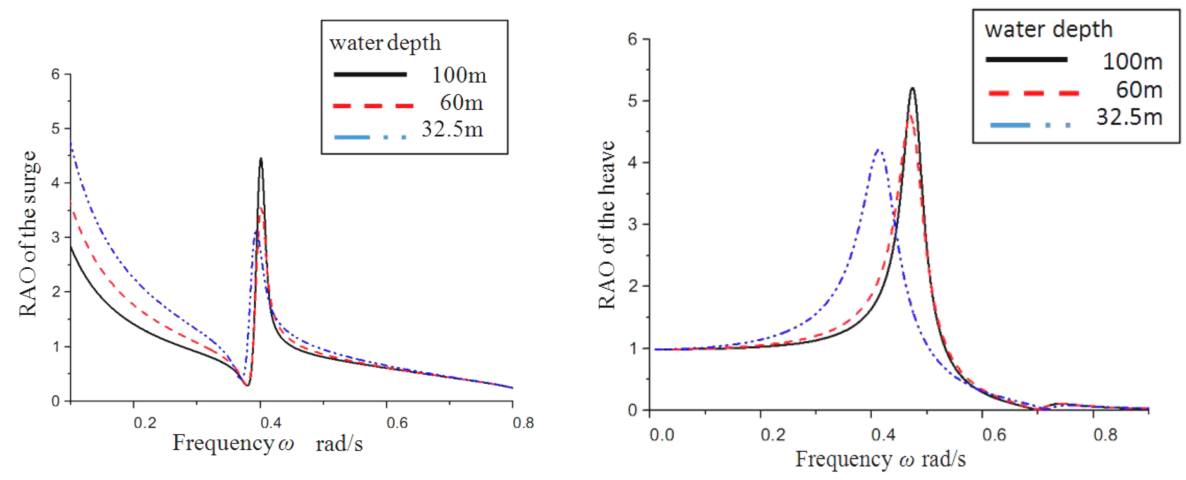

(a)

(b)

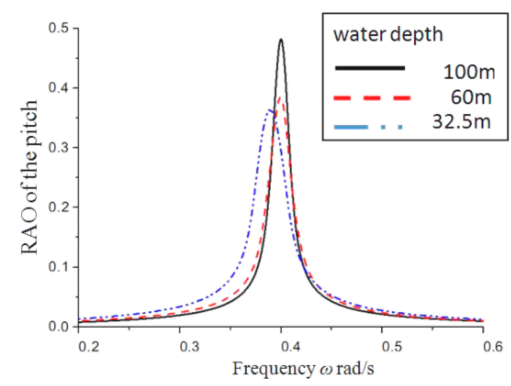

(c)

Figure 8. RAO of the platform with air cushion in different water depths. (a) Surge RAO; (b) heave RAO; (c) pitch RAO.

As seen from Figure 8a, the maximum surge RAO increases with the water depth, while the resonance frequency interval is barely affected by the water depth.

As seen from Figure $8 b, c$, the maximum heave (pitch) RAO increases with the water depth.Obviously, when the water depth is less than $60 \mathrm{~m}$, the increasing water depth significantly affects the resonance frequency interval by shifting the resonance interval from lower to higher frequency. 
In contrast, when the water depth is larger than $60 \mathrm{~m}$, the resonance frequency interval is almost not affected by the increasing water depth, though the maximum heave (pitch) RAO increases with water depth.

In a word, when the water depth is less than $60 \mathrm{~m}$, both the maximum RAO and the resonance frequency interval will be significantly affected by the water depth. However, with further increasing of the water depth, the influence on the resonance frequency interval can be ignored, while the maximum RAO still increases. The investigating results suggest that the zero-pressurized air-cushion-assisted barge platform has better performance in shallow water.

\subsection{Motion of the Zero-Pressurized Air-Cushion-Assisted Barge Platform in Irregular Waves}

To investigate the motion response of the zero-pressurized air-cushion-assisted barge platform in irregular waves, the Chinese offshore wave spectrum [20] was employed for simulating the real wave energy spectra, which is used to describe Chinese coastal waters. The expression of the China Sea spectrum is

$$
S_{\zeta}(\omega)=\frac{A}{\omega^{5}} \exp \left(-\frac{B}{\omega^{2}}\right)
$$

with

$$
\begin{gathered}
A=0.74 \\
B=\frac{\mathrm{g}^{2}}{6.28^{2} \cdot \bar{H}_{\frac{1}{3}}}
\end{gathered}
$$

where $\bar{H}_{\frac{1}{3}}$ is the significant wave height.

Figure 9 portrays the significant value of surge, heave, and pitch response of the platformwith air cushion in irregular waves of sea states from 2 to 6 .

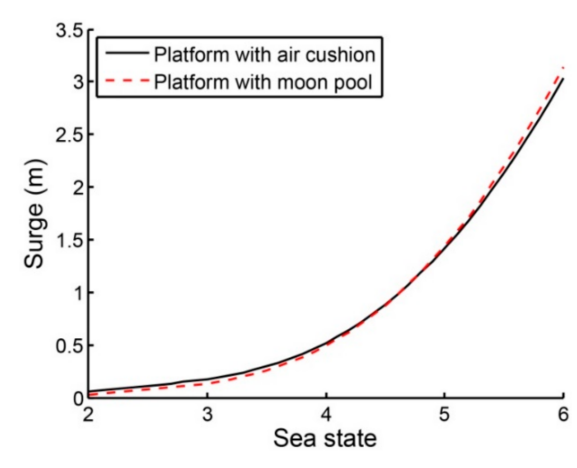

(a)

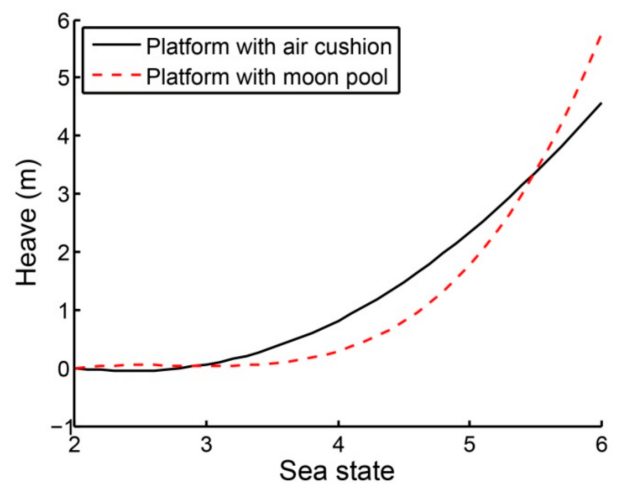

(b)

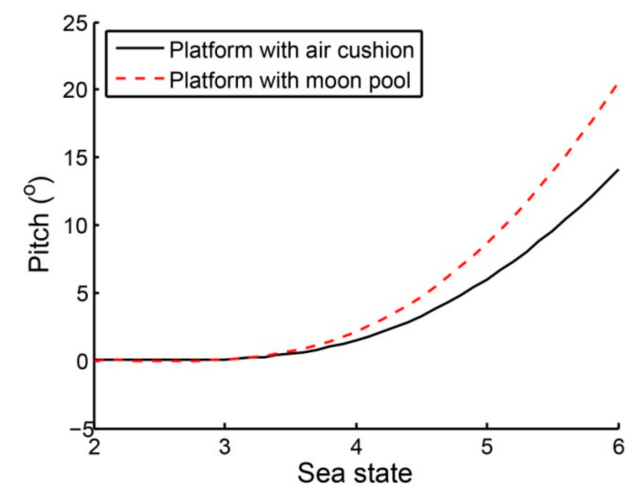

(c)

Figure 9. Significant value of motion response of the platforms in irregular waves. (a) Surge; (b) heave; (c) pitch. 
From Figure 9a, one can observe that the surge response of the platform with air cushion is slightly larger than the moon pool one in low sea states $(\leq 4)$, but smaller in high sea states $(\geq 5)$. Similarly, in Figure 9b, the heave response of the platform with air cushion is larger than the moon pool one when sea state is no more than 5 , but much smaller when sea state is beyond 6 . Finally, from Figure 9c, one finds that the pitch response of the platform with air cushion is always smaller than the moon pool one, and the pitch reduction effect increases with the sea state.

Therefore, the air cushion can reduce the overall motions of the barge platform in high sea states, but might bring negative effects to heave motion in low sea states.

\section{Conclusions}

In this paper, the hydrodynamic performance of a zero-pressurized air-cushion-assisted barge platform was studied. The definite problem for the air velocity potential in the cushion was firstly proposed and theopen-source Helmholtz solver BEMHELM was employed to solve it. Then the motion equations of the zero-pressurized air-cushion-assisted barge platformwereestablished, in which the hydrodynamic coefficient and wave force of the barge platform were solved by the commercial hydrodynamic software WAMIT. Finally, the motion responses of the barge platform in regular and irregular waves were studied and the following conclusions were obtained.

(1) The zero-pressurized air cushion has a significant suppression effect on heave and pitch motion of the barge platform in the vicinity of the resonance frequencies (about $50 \%$ of the maximum motion response can be reduced).

(2) With the reduction of water depth (from $60 \mathrm{~m}$ to $30 \mathrm{~m}$ ), the maximum motion RAO of the zero-pressurized air-cushion-assisted barge platform decreases, which suggests that the platform has excellent hydrodynamic performance in shallow water.

(3) The zero-pressurized air cushion can always reduce the pitch motion of the barge platform in irregular waves, as well as the heave motion in high sea states.However, the zero-pressurized air cushion might bring negative effects to heave motion in low sea states. One should carefully design the air cushion for barge platforms according to the operating sea states to achieve satisfactory hydrodynamic performance in engineering application.

Author Contributions: L.X. developed the theoretical method; Z.G. prepared the study cases; F.J. and H.L. performed the numerical calculation and analysis; and F.J. wrote the paper. All authors have read and agreed to the published version of the manuscript.

Funding: This research was funded by the National Natural Science Foundation of China (grant No.51779063, 51979065), State Key Laboratory of OceanEngineering (Shanghai Jiao Tong University) (Grant No.1913), and the Natural Science Foundation of Heilongjiang Province of China (Grant No. E2018025).

Conflicts of Interest: The authors declare no conflict of interest. The founding sponsors had no role in the design of the study; in the collection, analyses, or interpretation of data; in the writing of the manuscript, and in the decision to publish the results.

\section{References}

1. Borg, M.; Utrera Ortigado, E.; Collu, M.; Brennan, F.P. Passive damping systemsfor floating vertical axis wind turbines analysis. In Proceedings of the European Wind Energy Conference, EWEA, Vienna, Austria, 3-7 February 2013.

2. Pinkster, J.A.; Scholte, E.J.A.M. The behaviour of a large air-supported MOB at sea. Mar. Struct. 2001, 14, 163-179. [CrossRef]

3. Ikoma, T.; Masuda, K.; Rheem, C.K.; Maeda, H. Response Reduction of Motion and Steady Wave Drifting Forces of Floating Bodies Supported by Aircushions in Regular Waves: The 2nd Report-Response Characteristics in Oblique Waves. In Proceedings of the ASME 2007, International Conference on Offshore Mechanics and Arctic Engineering, San Diego, CA, USA, 10-15 June 2007; pp. 3-9.

4. Kurniawan, A.; Greaves, D.; Chaplin, J. Wave energy devices with compressible volumes. Proc. R. Soc. A 2014, 470, 20140559. [CrossRef] [PubMed] 
5. Pinkster, J.A.; Fauzi, A.; Inoue, Y.; Tabeta, S. The behaviour of large air cushion supported structures in waves. In Proceedings of the Second International Conference on Hydroelasticity in Marine Technology, Fukuoka, Japan, 1-3 December 1998; pp. 497-505.

6. Tabeta, S. Model Experiments on Barge Type Floating Structures Supported by Air Cushions; Ship Hydromechanics Laboratory Report 1125; Delft University of Technology: Delft, The Netherlands, 1998.

7. Ikoma, T.; Masuda, K.; Maeda, H.; Rheem, C. Hydroelastic Behavior of Air-Supported Flexible Floating Structures. In Proceedings of the 21st International Conference on OMAE'02, Oslo, Norway, 23-28 June 2002; Volume 2, pp. 745-752.

8. Kessel, J.V. Air-Cushion Supported Mega-Floaters. Ph.D. Thesis, Delft University of Technology, Delft, The Netherlands, 2010.

9. Lee, C.H.; Newman, J.N. Wave Effects on Large Floating Structures with Air Cushions. Mar. Struct. 2000, 13, 315-330. [CrossRef]

10. Lee, C.H.; Newman, J.N. An Extended Boundary Integral Equation for Structures with Oscillatory Free-Surface Pressure. Int. J. Offshore Polar Eng. 2016, 26, 41-47. [CrossRef]

11. Bie, S.A.; Shi, Z.M.; Wang, L.Y. Analysis of Floating Stability of Air Cushion Supported Structure at Small Inclination Angle. China Harb. Constr. 2001, 2, 31-35.

12. Zhang, J.L. Experimental Research on the Motion Performance of Air Supported Artificial Island Foundation Floating Towing; Tianjin University: Tianjin, China, 2011.

13. Yang, J.L.; Lin, Z.; Gao, Z.Y.; Li, P. A Study on the Motion of Partial Air Cushion Support Catamaran in Regular Head Waves. Water 2019, 11, 580. [CrossRef]

14. Yang, D.M.; Sun, Z.Y.; Jiang, Y.; Gao, Z.Y. A Study on the Air Cavity under a Stepped Planing Hull. J. Mar. Sci. Eng. 2019, 7, 468. [CrossRef]

15. Cucinotta, F.; Guglielmino, E.; Sfravara, F.; Strasser, C. Numerical and experimental investigation of a planing Air Cavity Ship and its air layer evolution. Ocean Eng. 2018, 152, 130-144. [CrossRef]

16. Cucinotta, F.; Guglielmino, E.; Sfravara, F. An experimental comparison between different artificial air cavity designs for a planing hull. Ocean Eng. 2017, 140, 233-243. [CrossRef]

17. Cucinotta, F.; Guglielmino, E.; Sfravara, F. A critical CAE analysis of the bottom shape of a multi stepped air cavity planing hull. Appl. Ocean Res. 2019, 82, 130-142. [CrossRef]

18. Nguyen, T.; Tran, T.; de Boer, H.; van den Berg, A.; Eilkel, J.C. Rotary-atomizer electric power generator. Phys. Rev. Appl. 2015, 3, 034005. [CrossRef]

19. Kirkup, S. The Boundary Element Method in Acoustics: A Survey. Appl. Sci. 2019, 9, 1642. [CrossRef]

20. Li, J.D. Seakeepness of Ships; Harbin Engineering University: Harbin, China, 1992; ISBN 7-81007-172-6/U.24. 